\title{
Body mass index in young children and allergic disease: gender differences in a longitudinal study
}

\author{
C. S. Murray ${ }^{1}$, D. Canoy ${ }^{2}$, I. Buchan ${ }^{2}$, A. Woodcock ${ }^{1}$, A. Simpson ${ }^{1}$ and A. Custovic ${ }^{1}$ \\ ${ }^{7}$ Manchester Academic Health Science Centre, NIHR Translational Research Facility in Respiratory Medicine, University Hospital of South Manchester NHS \\ Foundation Trust, The University of Manchester, Manchester, UK and ${ }^{2}$ Northwest Institute for Bio-Health Informatics, The University of Manchester, Manchester, UK
}

\section{Clinical \&t Experimental Allergy}

Correspondence:

Dr C. Murray, School of Translational

Medicine (Respiratory Group), The

University of Manchester, Education

and Research Building, 2nd Floor,

University Hospital of South

Manchester, Manchester M23 9LT, UK.

E-mail:

clare.murray@manchester.ac.uk Cite this as: C. S. Murray, D. Canoy,

I. Buchan, A. Woodcock, A. Simpson and

A. Custovic, Clinical \&t Experimental

Allergy, 2011 (41) 78-85.

\section{Summary}

Background The increase in allergic diseases has occurred in parallel with the obesity epidemic, suggesting a possible association.

Objective We investigated the relationship of body mass index (BMI) up to age 8 years with allergic disease within a birth cohort.

Methods Children were followed from birth and were reviewed at age 3, 5 and 8 years $(n=731$; male 406). Parents completed questionnaires; children were weighed, measured, skin prick tested and examined.

Results Increasing BMI at 3, 5 and 8 years increased the risk of current wheezing at the corresponding age (odds ratio [95\% confidence interval] per standardized deviation score: age 3, 1.26 [1.04-1.53], $P=0.02$; age 5, 1.33 [1.06-1.67], $P=0.02$; age 8, 1.27 [1.0-1.62], $P=0.05$ ). The effect of BMI on wheeze at age 8 years differed between boys and girls, with a significant positive association in girls, but not in boys ( $P=0.04$ for interaction). The effect of BMI at earlier ages on current or subsequent wheezing did not differ significantly between genders. Increasing BMI significantly increased the risk of physician-diagnosed eczema at age 5 (1.23 [1.04-1.47], $P=0.02)$ and $8(1.23$ [1.03-1.45], $P=0.02)$, with a significant interaction between gender and BMI at age $5(P=0.04)$. There was no association between BMI and sensitization. Being overweight at age 3 years was significantly associated with late-onset wheeze (3.83 [1.51-9.75], $P=0.005$ ), persistent wheeze (4.15 [2.07-8.32], $P<0.001)$ and persistent eczema (1.79 [1.03-3.13], $P=0.04$ ) in both boys and girls.

Conclusions Being overweight is associated with an increased risk of allergic disease in childhood. However, the strength of the association varies with the gender, age and atopic phenotype.

Keywords asthma, body mass index, eczema, obesity

Submitted 13 October 2009; revised 22 June 2010; accepted 23 June 2010

\section{Introduction}

The prevalence of asthma and other allergic diseases has been increasing over the past few decades even in young children [1]. The wide variations in asthma prevalence between populations and the rapid rise within a relatively short period of time suggest that environmental factors play a role. This rising trend in allergic disease has occurred in parallel with increasing prevalence in obesity, suggesting a possible association [2]. Furthermore, reduction in excess weight in adults has been associated with an improvement in the symptoms of airways obstruction [3]. Hence, it is plausible that excess fat may contribute to the pathogenesis or the clinical presentation of allergic diseases.

Age is likely to be an important co-factor when examining the association between obesity and asthma. Indeed, the majority of incident asthma occurs by the age of 6 years [4]. It has been suggested that the immune and respiratory systems are relatively immature during infancy, and that they continue to develop during early childhood [5]. The immune deviation towards a Th2 phenotype of allergic diseases has been observed in this age group, suggesting that this period of early growth and development could be susceptible to environmental influences. As there have been increasing trends in obesity 
among pre-schoolchildren [6], any obesity-related allergic diseases might have become more prevalent in these children.

Gender is also likely to be important when examining the relationship between allergic disease and obesity in young children. The prevalence of asthma is the highest in childhood and has a male predominance that reverses in adolescence [4]. There is less evidence of a gender difference in eczema presentation but a recent survey suggests a peak prevalence in infancy with a sharp decline to 6 years [4]. Females, however, show a further increase during adolescence, with rates in adulthood twice that of males. These patterns of presentations for asthma and eczema by age and gender suggest important gender-specific differences in disease predisposition and diagnosis.

Several studies have examined the association between body size and asthma in pre-schoolchildren, but the findings have been inconsistent, and were based mostly on cross-sectional study designs [7-10]. Moreover, prospective studies have been limited to older children or adolescents [11-15]. We therefore investigated the relationship between body size and asthma, wheeze, eczema and allergic sensitization in boys and girls, who were followed from birth until 8 years in a population-based, prospective birth-cohort study.

\section{Methods}

\section{Study design, setting and participants}

The Manchester Asthma and Allergy Study is an unselected population-based birth cohort. Details of the study design and protocol have been reported previously [16, 17]. Briefly, subjects were recruited prenatally by studying parents at antenatal clinics using skin testing and questionnaires. Children were followed from birth, and attended review clinics at age 3, 5 and 8 years. The study was approved by the Local Research Ethics Committee. Written informed consent was obtained from subjects' legal guardians.

\section{Definition of variables}

Growth data and measures of adiposity. Birth weight was obtained by a questionnaire. At each review clinic, we measured weight, without shoes or outer clothing (to nearest $0.01 \mathrm{~kg}$ ), using a weighing scale, and height (to nearest $0.1 \mathrm{~cm}$ ) using a stadiometer. Body mass index (BMI) was calculated as weight $/$ height $^{2}\left(\mathrm{~kg} / \mathrm{m}^{2}\right)$. We present BMI as standardized deviation scores (SDS) using the British Growth Reference (1990) [18]. We also designated each individual as 'normal weight' or 'overweight' using previously published international age specific cut-offs, which assign age and gender-specific cut-off values [19].
Wheeze. At review clinics, a validated questionnaire [20] was interviewer administered, to collect information on parentally reported symptoms, doctor diagnoses and parental smoking. According to parentally reported history of wheeze, current wheeze was defined as wheezing in the previous 12 (age 5, 8) or 6 (age 3) months. We further defined wheeze as transient (wheezed up to the 5th birthday and not beyond), late-onset (wheezing commenced after the 4th birthday) and persistent wheezing (wheezed throughout the first 8 years of life).

Asthma. Defined as parentally reported, physician-diagnosed asthma.

Eczema. Current eczema was defined as parentally reported eczema in the previous 12 months. Based on the questionnaire responses, we defined eczema as transient (eczema up to the 5th birthday and not beyond), late-onset (eczema commenced after the 4th birthday) and persistent eczema (eczema present throughout the first 8 years of life).

Atopic sensitization. At each follow-up visit, children were skin-prick tested (SPT) (Dermatophagoides pteronyssinus, cat, dog, grasses, moulds, milk and egg; Bayer Corporation, Elkahrt, IN, USA) and classed as sensitized if the weal diameter to any allergen was $3 \mathrm{~mm}$ or greater than the negative control.

\section{Statistical analyses}

Analysis was carried out using SPSS version 15 (Chicago, IL, USA). We used logistic regression to model various atopic symptoms as the outcome variable (wheeze, asthma, eczema and atopic sensitization) at 3, 5 and 8 years vs. BMI from age 3, 5 and 8 years. We used odds ratios (ORs) to estimate the relative odds of developing symptoms. In the multivariate models, potential confounders were chosen $a$ priori for wheeze and asthma (birth weight, gestational age, maternal and paternal asthma, parental atopy, maternal and paternal smoking, child's atopy and socio-economic status), for eczema (parental atopy, child's atopy and socioeconomic status) and for atopic sensitization (parental atopy and socio-economic status). We considered potential nonlinear associations between growth and atopic diseases. However, adding a quadratic term for the growth measures in the regression models did not alter our findings. Hence, we report our main findings using adiposity measures as continuous variables in the models. We present our results as the main effects with 95\% confidence intervals, and treat calculated probabilities $<0.05$ as statistically significant.

\section{Results}

We recruited 1211 parents during pregnancy. Of the resulting 1085 healthy full-term deliveries, 128 were 
prenatally randomized to an active 'environmental intervention' group (excluded from this analysis) and 957 were followed in the observational cohort. For the present analysis, we included 731 of the children who attended all follow-up visits and had complete data on weight and height/length at birth, 3, 5 and 8 years. The 226 children who were not included in this analysis did not differ significantly from those included in terms of gender, ethnicity, birth weight, gestational age, parental atopy, parental asthma or parental smoking. Table 1 shows the characteristics of the children included in the study. There were no significant differences in family history between boys and girls (e.g. maternal or paternal asthma, atopy or smoking). Wheeze, asthma and atopy, but not eczema, were more common in boys than in girls. There were no differences in the proportions of boys and girls who were obese in any age group; however, girls were more likely to be overweight than boys and this difference strengthened with age.

\section{Association between measures of adiposity and clinical outcomes}

Wheeze. Higher BMI was associated with an increased risk of wheezing in all children at each time-point (Table 2). The effect of BMI on wheeze at age 8 years differed between boys and girls ( $P=0.04$ for interaction). There was a significant positive association in girls, but not in boys at this age (Table 2). The effect of BMI at earlier ages on current wheezing did not differ significantly between genders $(P>0.1)$.

Measures of adiposity at age 3 years were investigated in relation to phenotypes of wheeze to ascertain whether being overweight early in life was associated with a pattern of wheezing. Phenotypes of wheeze were created using the data collected at the three clinical follow-up visits (transient $n=194$, late-onset $n=38$ and persistent wheeze $n=92$ ). In all children, being overweight at age 3 years was significantly associated with both late-onset (OR 3.8, $P=0.005$ ) and persistent wheezing (OR 4.2, $P<0.001$ ) (Table 3), with no significant interaction between being overweight or BMI and gender.

Asthma. In the entire population, higher BMI was significantly associated with asthma at age 3 (OR 1.54, $P=0.008$ ) and 8 years (OR 1.43, $P=0.03$ ) (Table 4). The effect of BMI at age 3 on current asthma did not differ significantly between genders ( $P>0.1$ for interaction). However, for asthma diagnosis at age 8 years, there was a significant association with BMI at all time-points, with a significant interaction between gender and BMI, indicating that increasing BMI increased the risk of asthma only in girls, but not in boys (Table 4).
Table 1. Baseline characteristics of the pre-schoolchildren in the Manchester Asthma and Allergy Study (MAAS) cohort

\begin{tabular}{|c|c|c|c|}
\hline & $\begin{array}{l}\text { Boys } \\
(N=406)\end{array}$ & $\begin{array}{l}\text { Girls } \\
(N=325)\end{array}$ & $P$-value \\
\hline \multicolumn{4}{|l|}{ At birth } \\
\hline Gestational age (weeks) & $39.9(1.7)$ & $39.9(1.5)$ & 0.82 \\
\hline Birth weight (g) & 3544 (509) & 3397 (505) & $<0.001$ \\
\hline \multicolumn{4}{|l|}{ Follow-up at age 3 years } \\
\hline Weight (kg) & $15.5(2)$ & $15.1(2)$ & 0.002 \\
\hline Height $(\mathrm{m})^{*}$ & $0.96(0.04)$ & $0.95(0.03)$ & 0.001 \\
\hline Body mass index $\left(\mathrm{kg} / \mathrm{m}^{2}\right)$ & $16.8(1.3)$ & $16.6(1.6)$ & 0.13 \\
\hline Body mass index $z$-score & $0.407(0.98)$ & $0.415(1.05)$ & 0.92 \\
\hline \% Overweight ( $n$ ) & $16(66)$ & $22(73)$ & 0.04 \\
\hline$\%$ Obese $(n)$ & $3(12)$ & $4(12)$ & 0.6 \\
\hline $\begin{array}{l}\% \text { Current wheeze age } 3 \text { years } \\
\text { (wheezed age 1-3 years) (n) }\end{array}$ & $45(184)$ & $28(91)$ & $<0.001$ \\
\hline$\%$ Current eczema at age 3 years $(n)^{\dagger}$ & $28(112)$ & $25(81)$ & 0.39 \\
\hline$\%$ Current asthma at age 3 years $(n)^{\dagger}$ & $16(63)$ & $7(24)$ & 0.001 \\
\hline \% Atopy ${ }^{\dagger}$ & $24(99)$ & $15(48)$ & 0.001 \\
\hline \multicolumn{4}{|l|}{ Follow-up at age 5 years } \\
\hline Weight (kg) & $20.0(3.0)$ & $19.8(3.1)$ & 0.04 \\
\hline Height (m) & $1.10(0.05)$ & $1.10(0.04)$ & 0.55 \\
\hline Body mass index $\left(\mathrm{kg} / \mathrm{m}^{2}\right)$ & $16.3(1.5)$ & $16.4(1.8)$ & 0.40 \\
\hline Body mass index $z$-score & $0.478(1.00)$ & $0.488(0.98)$ & 0.90 \\
\hline \% Overweight ( $n$ ) & $19(76)$ & $29(93)$ & 0.002 \\
\hline$\%$ Obese $(n)$ & $4(15)$ & $6(20)$ & 0.12 \\
\hline $\begin{array}{l}\% \text { Current wheeze age } 5 \text { years } \\
\text { (wheezed age } 4-5 \text { years) ( } n \text { ) }\end{array}$ & $24(96)$ & $16(51)$ & 0.007 \\
\hline$\%$ Current eczema at age 5 years $(n)^{\dagger}$ & $31(125)$ & 35 (113) & 0.29 \\
\hline$\%$ Current asthma at age 5 years $(n)^{\dagger}$ & $13(54)$ & $8(26)$ & 0.02 \\
\hline$\%$ Atopy $^{\dagger}$ & $33(132)$ & $19(62)$ & $<0.001$ \\
\hline \multicolumn{4}{|l|}{ Follow-up at age 8 years } \\
\hline Weight (kg) & $28.0(5.6)$ & $28.4(5.9)$ & 0.45 \\
\hline Height (m) & $1.28(0.06)$ & $1.28(5.3)$ & 0.18 \\
\hline Body mass index $\left(\mathrm{kg} / \mathrm{m}^{2}\right)$ & $16.9(2.3)$ & $17.2(2.7)$ & 0.07 \\
\hline Body mass index $Z$-score & $0.481(1.05)$ & $0.438(1.04)$ & 0.58 \\
\hline \% Overweight ( $n$ ) & $16(67)$ & $25(80)$ & 0.007 \\
\hline$\%$ Obese $(n)$ & $6(24)$ & $8(25)$ & 0.34 \\
\hline $\begin{array}{l}\text { \% Current wheeze age } 8 \text { years } \\
\text { (wheezed age 7-8 years) ( } n \text { ) }\end{array}$ & $19(76)$ & $13(43)$ & 0.05 \\
\hline$\%$ Current eczema at age 8 years $(n)^{\dagger}$ & $24(97)$ & $25(80)$ & 0.76 \\
\hline$\%$ Current asthma at age 8 years $(n)^{\dagger}$ & $11(45)$ & $7(24)$ & 0.08 \\
\hline$\%$ Atopy at age 8 years $(n)^{\ddagger}$ & 34 (138) & $23(74)$ & $<0.001$ \\
\hline
\end{tabular}

Data presented as means (SD) for continuous variables or percentage (number) for categorical variables; based on a $t$-test for continuous variables and a $\chi^{2}$-test for categorical variables.

*By skin prick testing.

†Physician diagnosed.

${ }^{\ddagger}$ Positive skin prick test to any allergen tested. Bold signifies $P<0.05$.

Eczema. In all children, in the multivariate model increasing BMI significantly increased the risk of physiciandiagnosed eczema at age 5 (OR 1.2, $P=0.02$ ) and 8 (OR 1.2, $P=0.02$ ) (Table 5). Although this association appeared to be stronger in girls, the interaction between gender and BMI was significant only at age 5 years $(P=0.04)$. 
Table 2. BMI, $z$-score and risk of wheezing in young children - multivariate analysis [covariates were birth weight, gestational age, maternal and paternal history of asthma, parental atopic status (by SPT), maternal and paternal smoking at relevant follow-up (at 3, 5 or 8 years), and child atopic status (by SPT) at relevant follow-up (at 3, 5 or 8 years) and socio-economic status]

\begin{tabular}{|c|c|c|c|c|c|c|c|}
\hline & \multicolumn{2}{|l|}{ All $(N=731)$} & \multicolumn{2}{|l|}{ Boys $(N=406)$} & \multicolumn{2}{|l|}{ Girls $(N=325)$} & \multirow{2}{*}{$\begin{array}{l}\text { Interaction: Gender } \\
\times \text { body size* } \\
P \text {-value }\end{array}$} \\
\hline & $\begin{array}{l}\text { Odds ratio } \\
(95 \% \mathrm{CI})\end{array}$ & $P$-value & $\begin{array}{l}\text { Odds ratio } \\
(95 \% \text { CI) }\end{array}$ & $P$-value & $\begin{array}{l}\text { Odds ratio } \\
(95 \% \mathrm{CI})\end{array}$ & $P$-value & \\
\hline Wheezing age $1-3$ years, $\%(n)$ & $37.6(275)$ & & $45(184)$ & & $28(91)$ & & \\
\hline BMI $z$-score at 3 years & $1.26(1.04,1.53)$ & 0.02 & $1.31(1.02,1.69)$ & 0.04 & $1.20(0.88,1.65)$ & 0.26 & 0.67 \\
\hline Wheezing age $4-5$ years, $\%(n)$ & $20.1(147)$ & & $23(96)$ & & $16(51)$ & & \\
\hline BMI $z$-score at 3 years & $1.19(0.95,1.50)$ & 0.13 & $1.18(0.87,1.62)$ & 0.29 & $1.13(0.78,1.64)$ & 0.51 & 0.54 \\
\hline BMI $z$-score at 5 years & $1.33(1.06,1.67)$ & 0.02 & $1.40(1.04,1.90)$ & 0.03 & $1.15(0.77,1.71)$ & 0.50 & 0.98 \\
\hline Wheezing age $7-8$ years, \% ( $n$ ) & $16.3(119)$ & & $19(76)$ & & $13(43)$ & & \\
\hline BMI $z$-score at 3 years & $1.14(0.87,1.48)$ & 0.34 & $1.17(0.81,1.69)$ & 0.41 & $1.07(0.71,1.60)$ & 0.76 & 0.68 \\
\hline BMI $z$-score at 5 years & $1.21(0.92,1.58)$ & 0.18 & $1.12(0.78,1.60)$ & 0.55 & $1.22(0.78,1.91)$ & 0.39 & 0.19 \\
\hline BMI $z$-score at 8 years & $1.27(1.0,1.62)^{*}$ & 0.05 & $1.09(0.79,1.51)$ & 0.60 & $1.52(1.01,2.28)$ & 0.04 & 0.04 \\
\hline
\end{tabular}

CI, confidence interval; BMI $z$-score - body mass index standard deviation score.

*Significant interaction between gender and BMI at age 8 and wheezing at age $7-8, P=0.04(1.67$ [1.03, 2.28]).

Bold signifies $P<0.05$.

SPT, skin prick test.

Table 3. Overweight at 3, 5 and 8 years and phenotypes of wheezing in children - multivariate analysis (covariates were birth weight, gestational age, maternal and paternal history of asthma, parental atopic status, maternal and paternal smoking, child's atopic status and socio-economic status)

\begin{tabular}{|c|c|c|c|c|c|c|c|}
\hline & \multicolumn{2}{|l|}{ All $(N=731)$} & \multicolumn{2}{|l|}{ Boys $(N=406)$} & \multicolumn{2}{|l|}{ Girls $(N=325)$} & \multirow{2}{*}{$\begin{array}{l}\text { Interaction: Gender } \\
\times \text { body size } \\
P \text {-value }\end{array}$} \\
\hline & $\begin{array}{l}\text { Odds ratio } \\
(95 \% \text { CI) }\end{array}$ & $P$-value & $\begin{array}{l}\text { Odds ratio } \\
(95 \% \text { CI) }\end{array}$ & $P$-value & $\begin{array}{l}\text { Odds ratio } \\
(95 \% \text { CI) }\end{array}$ & $P$-value & \\
\hline Transient wheezing & $n=194$ & & $n=122$ & & $n=72$ & & \\
\hline Overweight at 3 years & $0.84(0.46,1.51)$ & 0.56 & $0.45(0.18-1.14)$ & 0.09 & $1.08(0.45-2.58)$ & 0.86 & 0.05 \\
\hline Late-onset wheezing & $n=38$ & & $n=22$ & & $n=16$ & & \\
\hline Overweight at 3 years & $3.83(1.51,9.75)$ & 0.005 & $2.25(0.51-9.99)$ & 0.29 & $3.06(0.86-10.90)$ & 0.08 & 0.96 \\
\hline Persistent wheezing & $n=92$ & & $n=65$ & & $n=27$ & & \\
\hline Overweight at 3 years & $4.15(2.07,8.32)$ & $<0.001$ & $3.74(1.34-9.99)$ & 0.009 & $6.03(1.98-18.38)$ & 0.002 & 0.08 \\
\hline Transient early wheeze & $n=194$ & & $n=122$ & & $n=72$ & & \\
\hline BMI $z$-score at 3 years & $1.14(0.93,1.41)$ & 0.21 & $1.10(0.83,1.45)$ & 0.52 & $1.24(0.87,1.75)$ & 0.23 & 0.17 \\
\hline Late-onset wheeze & $n=38$ & & $n=22$ & & $n=16$ & & \\
\hline BMI $z$-score at 3 years & $1.36(0.90,2.04)$ & 0.14 & $1.06(0.61,1.83)$ & 0.84 & $1.34(0.78,2.32)$ & 0.29 & 0.60 \\
\hline Persistent wheeze & $n=92$ & & $n=65$ & & $n=27$ & & \\
\hline BMI $z$-score at 3 years & $1.60(1.17,2.20)$ & 0.003 & $1.52(1.02,2.26)$ & 0.04 & $1.86(1.07,3.24)$ & 0.03 & 0.11 \\
\hline
\end{tabular}

Bold signifies $P<0.05$.

CI, confidence interval; BMI, body mass index.

Being overweight at age 3 years was a risk factor for the persistence of eczema to age 8 in both univariate and multivariate models (Table 5). Again, the relationship appeared to be stronger in girls than in boys, but the interaction between measures of adiposity and gender was not statistically significant. However, for late-onset eczema, we observed a significant interaction between BMI at age 3 and gender, indicating that BMI increased the risk of late-onset eczema in girls but not in boys (Table 5).

Atopic sensitization. We found no association between BMI and atopy.

\section{Discussion}

\section{Principal findings}

In this population-based birth cohort of children who were followed from birth to age 8 years, increased BMI was associated with an increased risk of wheezing and eczema, but not atopic sensitization. The strength of the associations varied with sex and the timing of assessing the outcome. Increased BMI was associated with an increased risk of wheeze and asthma in both boys and girls. However, with increasing age, the effect of BMI on the risk of wheezing and asthma increased significantly 
Table 4. BMI $z$-score and risk of physician-diagnosed asthma in young children - multivariate analysis [covariates were birth weight, gestational age, maternal and paternal history of asthma, parental atopic status (by SPT), maternal and paternal smoking at relevant follow-up (at 3, 5 or 8 years), and child atopic status (by SPT) at relevant follow-up (at 3, 5 or 8 years) and socio-economic status]

\begin{tabular}{|c|c|c|c|c|c|c|c|}
\hline & \multicolumn{2}{|l|}{ All $(N=731)$} & \multicolumn{2}{|l|}{ Boys $(N=406)$} & \multicolumn{2}{|l|}{ Girls $(N=325)$} & \multirow{2}{*}{$\begin{array}{l}\text { Interaction: Gender } \\
\times \text { body size* }^{*} \\
P \text {-value }\end{array}$} \\
\hline & $\begin{array}{l}\text { Odds ratio } \\
\text { (95\% CI) }\end{array}$ & $P$-value & $\begin{array}{l}\text { Odds ratio } \\
\text { (95\% CI) }\end{array}$ & $P$-value & $\begin{array}{l}\text { Odds ratio } \\
\text { (95\% CI) }\end{array}$ & $P$-value & \\
\hline Current asthma at age $3, \%(n)$ & $11.9(87)$ & & $16(63)$ & & $7(24)$ & & \\
\hline BMI $z$-score at 3 years & $1.54(1.12,2.13)$ & 0.008 & $1.53(1.03,2.28)$ & 0.04 & $1.43(0.78,2.58)$ & 0.23 & 0.75 \\
\hline Current asthma at age $5, \%(n)$ & $10.9(80)$ & & $13(54)$ & & $8(26)$ & & \\
\hline BMI $z$-score at 3 years & $1.23(0.91,1.66)$ & 0.17 & $1.15(0.77,1.71)$ & 0.50 & $1.34(0.78,2.31)$ & 0.29 & 0.28 \\
\hline BMI $z$-score at 5 years & $1.19(0.86,1.60)$ & 0.25 & $1.16(0.80,1.68)$ & 0.44 & $1.13(0.64,2.00)$ & 0.67 & 0.59 \\
\hline Current asthma at age $8, \%(n)$ & $9.4(69)$ & & $11(45)$ & & $7(24)$ & & \\
\hline BMI $z$-score at 3 years & $1.50(1.03,2.20)^{*}$ & 0.04 & $1.19(0.71,1.99)$ & 0.52 & $2.47(1.16,5.25)$ & 0.02 & 0.03 \\
\hline BMI $z$-score at 5 years & $1.69(1.15,2.48)^{*}$ & 0.008 & $1.40(0.83,2.38)$ & 0.21 & $2.60(1.23,5.51)$ & 0.01 & 0.03 \\
\hline BMI $z$-score at 8 years & $1.43(1.04,1.97)^{*}$ & 0.03 & $1.20(0.77,1.87)$ & 0.43 & $2.20(1.20,4.05)$ & 0.01 & 0.03 \\
\hline
\end{tabular}

Bold signifies $P<0.05$.

CI, confidence interval; BMI, body mass index.

* Significant interaction between gender and BMI at 3, 5 and 8 years and current asthma at age 8.

Table 5. BMI $z$-score and risk of physician-diagnosed eczema in young children; overweight status at various ages and eczema phenotypes multivariate analysis [covariates were parental atopic status (by SPT), child's atopic status (by SPT) at relevant follow-up (at 3, 5 or 8 years) and socioeconomic status]

\begin{tabular}{|c|c|c|c|c|c|c|c|}
\hline & \multicolumn{2}{|l|}{ All $(N=731)$} & \multicolumn{2}{|l|}{ Boys $(N=395)$} & \multicolumn{2}{|l|}{ Girls $(N=325)$} & \multirow{2}{*}{$\begin{array}{l}\text { Interaction: } \\
\text { Gender } \times \text { body size } \\
P \text {-value }\end{array}$} \\
\hline & $\begin{array}{l}\text { Odds ratio } \\
\text { (95\% CI) }\end{array}$ & $P$-value & $\begin{array}{l}\text { Odds ratio } \\
(95 \% \text { CI) }\end{array}$ & $P$-value & $\begin{array}{l}\text { Odds ratio } \\
\text { (95\% CI) }\end{array}$ & $P$-value & \\
\hline Current eczema at 3, \% (n) & 26.4 (193) & & $28(112)$ & & $25(81)$ & & \\
\hline BMI $z$-score at 3 years & $1.01(0.84,1.21)$ & 0.88 & 0.96 (0.74 to 1.23$)$ & 0.73 & 1.05 (0.81 to 1.36 ) & 0.70 & 0.70 \\
\hline Current eczema at 5, \% (n) & $32.6(238)$ & & $31(125)$ & & 35 (113) & & \\
\hline BMI $z$-score at 3 years & $1.18(1.00,1.39)$ & 0.05 & 1.01 (0.80 to 1.28$)$ & 0.95 & 1.41 (1.10 to 1.80$)$ & 0.007 & 0.07 \\
\hline BMI $z$-score at 5 years & $1.23(1.04,1.47)$ & 0.02 & 1.04 (0.82 to 1.32$)$ & 0.73 & 1.55 (1.18 to 2.03$)$ & 0.002 & 0.04 \\
\hline Current eczema at $8, \%(n)$ & $24.2(177)$ & & $24(97)$ & & $25(80)$ & & \\
\hline BMI $z$-score at 3 years & $1.29(1.07,1.55)$ & 0.008 & $1.15(0.88-1.50)$ & 0.30 & $1.42(1.08-1.86$ & 0.01 & 0.34 \\
\hline BMI $z$-score at 5 years & $1.30(1.08,1.57)$ & 0.006 & $1.30(0.87-1.46)$ & 0.35 & $1.53(1.15-2.04)$ & 0.004 & 0.17 \\
\hline BMI $z$-score at 8 years & $1.23(1.03,1.45)$ & 0.022 & $1.06(0.83-1.34)$ & 0.62 & $1.41(1.09-1.84)$ & 0.01 & 0.19 \\
\hline Transient eczema & & & $26(102)$ & & $25(80)$ & & \\
\hline Overweight at 3 years & $0.99(0.57,1.71)$ & 0.97 & $0.91(0.42-1.99)$ & 0.81 & $1.07(0.48-2.40)$ & 0.86 & 0.71 \\
\hline Late onset eczema & & & $5(19)$ & & $8(26)$ & & \\
\hline Overweight at 3 years & $1.74(0.75,4.08)$ & 0.20 & $0.36(0.04-2.91)$ & 0.34 & $2.94(1.04-8.32)$ & 0.04 & 0.10 \\
\hline Persistent eczema & & & $20(78)$ & & $18(58)$ & & \\
\hline Overweight at 3 years & $1.79(1.03,3.13)$ & 0.04 & $1.07(0.43-2.66)$ & 0.88 & $2.71(1.22-6.03)$ & 0.01 & 0.34 \\
\hline Transient eczema, \% (n) & & & $26(102)$ & & $25(80)$ & & \\
\hline BMI $z$-score at 3 years & $1.01(0.83,1.24)$ & 0.90 & $1.00(0.75,1.35)$ & 0.99 & $1.02(0.75,1.38)$ & 0.91 & 0.93 \\
\hline Late onset eczema, \% (n) & & & $5(19)$ & & $8(26)$ & & \\
\hline BMI $z$-score at 3 years & $1.53(1.04,2.24)$ & 0.03 & $0.93(0.51,1.68)$ & 0.80 & $2.34(1.32,4.13)$ & 0.004 & 0.04 \\
\hline Persistent eczema, \% ( $n$ ) & & & $20(78)$ & & $18(58)$ & & \\
\hline BMI $z$-score at 3 years & $1.24(0.99,1.57)$ & 0.06 & $1.16(0.84,1.62)$ & 0.37 & $1.35(0.97,1.89)$ & 0.08 & 0.58 \\
\hline
\end{tabular}

Bold signifies $P<0.05$.

CI, confidence interval; BMI, body mass index.

for girls compared with boys. Being overweight early in life (age 3 years) increased the risk of both late-onset and persistent wheeze in both sexes. Similarly, the risk of eczema at age 5 and 8 years increased with increasing BMI. Although the associations appeared stronger in girls than in boys, the only significant interaction between gender and BMI was observed with current eczema at age 5. Being overweight at age 3 increased the odds for persistence of eczema up to age 8 years and increasing BMI at age 3 increased the odds for late-onset eczema. We 
observed a significant interaction between BMI at age 3 and gender, which suggested that BMI increased the risk of late-onset eczema only in girls.

\section{Limitations of the study}

Although we attempted to minimize residual confounding by taking into account a number of potential confounders, including parental atopy, parental smoking, parental asthma, gestational age and birth weight, we were unable to adjust for physical activity. However, one may speculate that, considering that we are looking at very young children, a sedentary lifestyle is less likely to influence our findings. Clearly, activity levels may have had an effect. We also did not assess the role of dietary factors.

Our study relies on parental reporting of wheeze, which might be over-reported as parents can misinterpret other respiratory sounds for wheeze [21]. Also, we did not distinguish between those who had wheezed just once or twice in the time period and those who had wheezed frequently. However, it is of note that our findings for physician-diagnosed asthma were similar to those for parentally reported wheeze.

In addition, we cannot exclude the possibility of sexrelated biases in diagnosing asthma and reporting of symptoms. Our study may not have enough power to detect smaller effects of obesity, considering that we only used BMI as a surrogate marker for adiposity, and to test for potential interactions between obesity and environmental determinants of allergic disease. It would appear that BMI has a greater association with wheeze and asthma in girls as they become older. Our data suggest that this may also possibly be the case for girls and eczema but the study may have had insufficient power to show this.

\section{Interpretation of the study}

It has been suggested that allergic diseases have their origins in early life, and that the priming of the immune system starts in utero [22]. This immune deviation towards a Th2 phenotype of allergic diseases continues after birth, through infancy and early childhood [5]. The immune system is immature in the neonatal period, and could be susceptible to environmental influences. Hence, the early postnatal period could be a critical period during which excess fat may influence the pathogenesis or the expression of allergic diseases, particularly among susceptible individuals. Indeed, our findings suggest that excess weight is associated with allergic symptoms, even in early childhood.

Despite the potential impact of excess fat on the development of the immune system in early childhood, few studies have focused on pre-schoolchildren, and the findings from relevant cross-sectional studies have been inconsistent. Among 2- to 5-year-old children, a positive but weak association was observed between BMI and asthma in one study [7], but not in another [8]. Another study among 0.5- to 11-year-old children showed that BMI was associated with wheeze but not with doctordiagnosed asthma, but the results were not reported specifically for pre-schoolchildren [9]. A case-control study of 2- to 18-year-old children also suggested an increased risk of obesity among asthma cases, but there was no specific risk estimate for the pre-school age group [10]. Our study differed in that we were able to assess, prospectively, the relationship between body size and allergic disease in very young boys and girls.

The lack of an association between adiposity and atopic sensitization, which has also been observed in ours and in other studies, suggests that the underlying biological pathway may involve non-eosinophil inflammatory mechanisms [23]. Pro-inflammatory cytokines such as IL6 and TNF- $\alpha$ are known to be involved in the pathogenesis of asthma and eczema, and in the severity and persistence of symptoms [24, 25]. The expression and production of these cytokines by adipocytes are likely increased in obesity [26]. There is also some evidence to suggest that obesity is associated with increased bronchial reactivity [27]; hence, both inflammation and airway obstruction could result in increased wheeze symptoms in obesity.

In addition, adipose tissue secretes bioactive peptides such as leptin and adiponectin, which are known as adipokines. Leptin production correlates with BMI by regulating food intake and metabolism [28]. Leptin receptors are expressed in the lung [29], and higher leptin levels have been demonstrated in asthmatic children compared with controls [30]. However, leptin levels in cord blood were not associated with asthma in two-year-old children [31]. In addition, serum leptin levels were not associated with rhinoconjunctivitis or eczema in schoolchildren [30]. Adiponectin, on the other hand, is inversely associated with obesity in children [32]. In children of atopic mothers, adiponectin levels in cord blood were inversely associated with physician-diagnosed asthma at age 2 years [31]. Also, serum levels in 10-year-old children have been shown to be inversely associated with the prevalence of eczema, but not wheeze or rhinoconjunctivitis [30]. Nagel et al. [30] reported much stronger associations in girls than in boys, both for leptin levels and asthma and for adiponectin levels and eczema. Thus, it would appear that the levels of these adipokines are associated with different allergic diseases at different ages and are perhaps stronger in girls.

This may help to explain some of the difference in the magnitude of the effect we observed between the sexes. A recent Japanese study has also reported variable associations of obesity on asthma and allergic rhinitis in boys and girls [33]. Measures such as weight or BMI are known 
indicators of adiposity [34], but fatness varies widely, and girls tend to have more fat than boys at a given BMI [35]. Girls would be expected to have higher exposure to inflammation than boys for a given increase in BMI. This may also explain why we observed a stronger association of BMI with age in girls and wheezing and asthma.

It has also been suggested that postnatal somatic growth exceeds growth in pulmonary function, and thus those young children who gain weight rapidly early in life may have reduced lung function, and are thus more susceptible to wheeze symptoms [36]. It is important to note that determinants of airway size (both large and small) are different between the sexes, with boys' airway growth being largely dependent on parenchymal growth, and girls' largely dependent on somatic growth and maturation [37]. In addition, pubertal growth effects on airways are different between the sexes [37]. Thus, it is not surprising that the effects of being overweight and airway disease may differ between the sexes, and at different ages in childhood.

\section{Conclusions}

Being overweight is associated with an increased risk of allergic disease in childhood, but the strength of the association varies with gender, age and the specific allergic phenotype. Being overweight early in life increases the risk of the subsequent onset of wheeze among children who have not wheezed, and the persistence of wheeze among those who have. Markers of adiposity were also associated with eczema, but not with atopic sensitization. These associations appeared to be stronger in girls as children approached middle childhood.

It is possible that children who remain overweight might be at a higher risk of persistent symptoms later in life. Early childhood could be a window of opportunity for prevention, and there is a need to examine whether preventing excess weight gain or reducing excess weight in young children could reduce the risk of allergic disease.

\section{Acknowledgements}

The authors would like to thank the children and parents of the Manchester asthma and allergy study for their participation, and Gina Kerry, Katy Johnson, Patricia Kissen and Bridget Simpson for the clinical follow-up of the cohort.

Funding: M. A. A. S. was supported by Asthma UK Grant No 04/014 and Moulton Charitable Trust, and is currently supported by MRC Grant G0601361.

\section{References}

1 Asher MI, Montefort S, Bjorksten B et al. Worldwide time trends in the prevalence of symptoms of asthma, allergic rhinoconjunc- tivitis, and eczema in childhood: ISAAC phases one and three repeat multicountry cross-sectional surveys. Lancet 2006; 368:733-43.

2 Chinn S, Rona RJ. Can the increase in body mass index explain the rising trend in asthma in children? Thorax 2001; 56:845-50.

3 Stenius-Aarniala B, Poussa T, Kvarnstrom J, Gronlund EL, Ylikahri M, Mustajoki P. Immediate and long term effects of weight reduction in obese people with asthma: randomised controlled study. Br Med J 2000; 320:827-32.

4 Osman M, Hansell AL, Simpson CR, Hollowell J, Helms PJ. Gender-specific presentations for asthma, allergic rhinitis and eczema in primary care. Prim Care Respir J 2007; 16:28-35.

5 Yabuhara A, Macaubas C, Prescott SL et al. TH2-polarized immunological memory to inhalant allergens in atopics is established during infancy and early childhood. Clin Exp Allergy 1997; 27:1261-9.

6 Bundred P, Kitchiner D, Buchan I. Prevalence of overweight and obese children between 1989 and 1998: population based series of cross sectional studies. Br Med J 2001; 322:326-8.

7 Kwon HL, Ortiz B, Swaner R et al. Harlem children's zone asthma initiative. Childhood asthma and extreme values of body mass index: the Harlem children's zone asthma initiative. J Urban Health 2006; 83:421-33.

8 Romieu I, Mannino DM, Redd SC, McGeehin MA. Dietary intake, physical activity, body mass index, and childhood asthma in the third National Health and Nutrition Survey (NHANES III). Pediatr Pulmonol 2004; 38:31-42.

9 Schwartz J, Gold D, Dockery DW, Weiss ST, Speizer FE. Predictors of asthma and persistent wheeze in a national sample of children in the United States. Association with social class, perinatal events, and race. Am Rev Respir Dis 1990; 142:555-62.

10 Luder E, Melnik TA, DiMaio M. Association of being overweight with greater asthma symptoms in inner city black and hispanic children. J Pediatr 1998; 132:699-703.

11 Hancox RJ, Milne BJ, Poulton R et al. Sex differences in the relation between body mass index and asthma and atopy in a birth cohort. Am J Respir Crit Care Med 2005; 171:440-5.

12 Gilliland FD, Berhane K, Islam T et al. Obesity and the risk of newly diagnosed asthma in school-age children. Am J Epidemiol 2003; 158:406-15.

13 Gold DR, Damokosh AI, Dockery DW, Berkey CS. Body-mass index as a predictor of incident asthma in a prospective cohort of children. Pediatr Pulmonol 2003; 36:514-21.

14 Castro-Rodriguez JA, Holberg CJ, Morgan WJ, Wright AL, Martinez FD. Increased incidence of asthma like symptoms in girls who become overweight or obese during the school years. Am J Respir Crit Care Med 2001; 163:1344-9.

15 Mamun AA, Lawlor DA, Alati R, O'Callaghan MJ, Williams GM, Najman JM. Increasing body mass index from age 5 to 14 years predicts asthma among adolescents: evidence from a birth cohort study. Int J Obes (London) 2007; 31:578-83.

16 Custovic A, Simpson BM, Murray CS, Lowe L, Woodcock A. The national asthma campaign Manchester asthma and allergy study. Pediatr Allergy Immunol 2002; 13 (Suppl. 15):32-7.

17 Murray CS, Woodcock A, Smillie FI, Cain G, Kissen P, Custovic A. Tobacco smoke exposure, wheeze, and atopy. Pediatr Pulmonol 2004; 37:492-8.

18 Cole TJ, Freeman JV, Preece MA. BMI reference curves for the UK, 1990. Arch Dis Child 1995; 73:25-9. 
19 Cole TJ, Bellizzi MC, Flegal KM, Dietz WH. Establishing a standard definition for child overweight and obesity worldwide: international survey. Br Med J 2000; 320:1-6.

20 Ferris BG. Epidemiology standardization project (American Thoracic Society). Am Rev Respir Dis 1978; 118:1-120.

21 Lowe L, Murray CS, Martin L et al. Reported versus confirmed wheeze and lung function in early life. Arch Dis Child 2004; 89:540-3.

22 Smillie FI, Elderfield AJ, Patel F et al. Lymphoproliferative responses in cord blood and at one year: no evidence for the effect of in utero exposure to dust mite allergens. Clin Exp Allergy 2001; 31:1194-204.

23 Krawiec ME, Westcott JY, Chu HW et al. Persistent wheezing in very young children is associated with lower respiratory inflammation. Am J Respir Crit Care Med 2001; 163:1338-43.

24 Chung KF, Barnes PJ. Cytokines in asthma. Thorax 1999; 54: 825-57.

25 Allam JP, Novak N. The pathophysiology of atopic eczema. Clin Exp Dermatol 2006; 1:89-93.

26 Bastard JP, Jardel C, Delattre J, Hainque B, Bruckert E, Oberlin F. Evidence for a link between adipose tissue interleukin- 6 content and serum C-reactive protein concentrations in obese subjects. Circulation 1999; 99:2221-2.

27 Chinn S, Jarvis D, Burney P. Relation of bronchial responsiveness to body mass index in the ECRHS. European Community Respiratory Health Survey. Thorax 2002; 57:1028-33.

28 Friedman JM, Halaas JL. Leptin and regulation of body weight in mammals. Nature 1998; 395:763-70.
29 Tsuchiya T, Shimizu H, Horie T, Mori M. Expression of leptin receptor in lung: leptin as a growth factor. Eur J Pharmacol 1999; 4:371-9.

30 Nagel G, Koenig W, Rapp K, Wabitsch M, Zoellner I, Weiland SK. Associations of adipokines with asthma, rhinoconjunctivitis and eczema in German schoolchildren. Pediatr Allergy Immunol 2009; 20:81-8.

31 Rothenbacher D, Weyermann M, Fantuzzi G, Brenner H. Adipokines in cord blood and risk of wheezing disorders within the first two years of life. Clin Exp Allergy 2007; 37:1143-9.

32 Asayama K, Hayashibe H, Dobashi K et al. Decrease in serum adiponectin level due to obesity and visceral fat accumulation in children. Obes Res 2003; 11:1072-9.

33 Kusunoki T, Morimoto T, Nishikomori R et al. Obesity and the prevalence of allergic diseases in school children. Pediatr Allergy Immunol 2008; 19:527-34.

34 Dietz WH, Robinson TN. Use of the body mass index (BMI) as a measure of overweight in children and adolescents. J Pediatr 1998; 132:191-3.

35 Daniels SR, Khoury PR, Morrison JA. The utility of body mass index as a measure of body fatness in children and adolescents: differences by race and gender. Pediatrics 1997; 99:804-7.

36 Turner S, Zhang G, Young S et al. Associations between postnatal weight gain, change in postnatal pulmonary function, formula feeding and early asthma. Thorax 2008; 63:234-9.

37 Becklake MR, Kauffmann F. Gender differences in airway behaviour over the human life span. Thorax 1999; 54:1119-38. 